ORIGINAL ARTICLE

\title{
Reliability and validity of health status measurement by the TAPQOL
}

\author{
E M Bunge, M-L Essink-Bot, M P H M Kobussen, L W A van Suijlekom-Smit, H A Moll, H Raat
}

Arch Dis Child 2005;90:351-358. doi: 10.1136/adc.2003.048645

See end of article for authors' affiliations .....................

Correspondence to: Ms E Bunge, Department of Public Health, Erasmus MC, University Medical Center Rotterdam, PO Box $1738,3000 \mathrm{DR}$

Rotterdam, Netherlands; e.bunge@erasmusmc.nl

Accepted 11 October 2004
Background: In addition to clinical measures in the evaluation of paediatric interventions, health related quality of life (HRQoL) is an important outcome. The TAPQOL (TNO-AZL Preschool children Quality of Life) was developed to measure HRQoL in preschool children. It is a generic instrument consisting of 12 scales that cover the domains physical, social, cognitive, and emotional functioning.

Aims: To evaluate the feasibility, score distribution, internal consistency, test-retest reliability, and discriminative and concurrent validity of the TAPQOL multi-item scales in preschool children, aged 2-48 months. Also to evaluate the feasibility, reliability, and validity separately for infants (2-12 months old) and toddlers (12-48 months old).

Methods: Parents of a random general population sample of 500 preschool children were sent a questionnaire by mail. A random subgroup of 159 parents who participated received a retest after two weeks.

Results: The response rate was $83 \%$ at the test and $75 \%$ at the retest. There were few missing answers. Six scales showed ceiling effects. Nine scales had Cronbach's alphas $>0.70$. In general, score distributions and Cronbach's alphas were comparable for infants and toddlers. Test-retest showed no significant differences in mean scale scores; two scales had intra-class correlations $<0.50$. Five scales showed significant differences between children with no conditions versus children with two or more parent reported chronic conditions.

Conclusion: Results showed that the TAPQOL is a feasible instrument to measure HRQoL and support the reliability and discriminative validity of the majority of its scales for infants as well as toddlers.
$\mathrm{H}$ ealth status and health related quality of life (HRQoL) measures are used for the evaluation of healthcare intervention in community medicine and clinical practice. ${ }^{1-6}$ Furthermore, HRQoL measures are used for descriptive studies; for example, burden of disease studies in public health ${ }^{78}$ and follow up studies of distinct patients groups. ${ }^{9}$ In the future, possibilities may arise for applications in daily medical practice in both community and clinical medicine. ${ }^{10}$

Few HRQoL measures are available for preschool children. ${ }^{11-17}$ A reason for this might be that young children show a fast development of cognitive, motor, and behavioural functions, especially during the first years of life. ${ }^{18}$ This means that instruments which intend to cover a relatively wide age range (for example, 0-4 years) have to somehow accommodate for this.

The TAPQOL is the first multi-dimensional HRQoL measure that was specifically designed for preschool children aged 1-5 years. ${ }^{14-17}$ As preschool children cannot complete questionnaires by themselves, the TAPQOL uses a proxy, mostly a parent. In this study we evaluated the psychometric properties of the TAPQOL including, for the first time, assessment of the test-retest reliability. Additionally, also for the first time, we applied the TAPQOL to infants (2-12 months old) and specifically evaluated its performance in this subgroup.

The aim of this study was to evaluate the feasibility, score distribution, internal consistency, test-retest reliability, and discriminative and concurrent validity of the TAPQOL multiitem scales in preschool children, aged 2-48 months. In addition, the feasibility, reliability, and validity were evaluated separately for infants (2-12 months old) and toddlers (12-48 months old).

\section{METHODS}

The Medical Ethical Committee of the Erasmus MC, University Medical Center Rotterdam, approved this study.

\section{Population and data collection}

Parents of a random general population sample of 500 preschool children (2-48 months old) in the eastern part of the Netherlands were sent the TAPQOL questionnaire by mail. The parents themselves decided which parent should participate. In case of non-response each household received maximally two reminder letters; no incentives to participate were given. Two weeks later, a random subgroup of 158 participating parents received the same questionnaire to assess test-retest reliability. The completed TAPQOL questionnaires were returned by mail.

Only parents who were considered to be able to adequately read and write Dutch were eligible for analysis. This was operationalised as at least one parent being Dutch or, if both parents were of foreign origin, that they should have an education of higher vocational level or have a university degree.

\section{Questionnaire}

The TAPQOL is a 43 item questionnaire consisting of 12 multi-item scales that cover the domains physical, social, cognitive, and emotional functioning (see fig 1). The number of items per scale ranges from three to seven. TAPQOL items generally relate to the past three months, but this may be adjusted for specific research aims. For all scales, the presence of a specific complaint or limitation was scored on a three point scale, namely "never", "occasionally", and "often". For seven TAPQOL scales ("stomach problems", "skin problems", "lung problems", "sleeping", "appetite", 
PHYSICAL FUNCTIONING

Sleeping

How did your child sleep...

Appetite

How did your child eat and drink...

Lungs

Has your child had.../Has your child been...

\section{Stomach}

Has your child had.../Has your child been...

\section{Skin}

Has your child had...

Motor functioning

Did your child have...

\section{SOCIAL FUNCTIONING}

\section{Social functioning}

How was your child's behaviour with older children

\section{Problem behaviour}

Your child's behaviour...

\section{COGNITIVE FUNCTIONING}

\section{Communication}

Did your child have...

\section{EMOTIONAL FUNCTIONING \\ Anxiety}

How was your child...

Positive mood

How was your child...

\section{Liveliness}

How was your child...

Reprinted with permission of Fekkes et al ${ }^{19}$.

Figure 1 ltems on the TAPQOL questionnaire.

"motor functioning", and "communication"), first the presence of a specific complaint or limitation is recorded and, if this is the case, the wellbeing of the child related to that complaint or limitation is measured on a four point scale, namely "fine", "not so good", "quite bad", and "bad". Scale scores we calculated by adding up item scores within scales, and transforming crude scales scores linearly to a
(1) did your child sleep restlessly

(2) was your child awake at night

(3) did your child cry at night

(4) did your child have difficulty sleeping through the night

(5) was your child's appetite poor

(6) did your child have difficulty eating enough

(7) did your child refuse to eat

(8) bronchitis

(9) difficulty breathing or lung problems

(10) short of breath

(11) stomach ache or abdominal pain

(12) colic

(13) nauseous

(14) eczema

(15) itchiness

(16) dry child

(17) difficulty with walking

(18) difficulty with running

(19) difficulty with walking up stairs without help

(20) difficulty with balance

(21) my child was able to play happily with other children

(22) my child was at ease with other children

(23) my child was confident with other children

(24) my child was short-tempered

(25) my child was aggressive

(26) my child was irritable

(27) my child was angry

(28) my child was restless or impatient with me

(29) my child was defiant/awkward with me

(30) I could not manage my child

(31) difficulty in understanding what others said

(32) difficulty in talking clearly

(33) difficulty in saying what he/she meant

(34) difficulty in making it clear what he/she wanted

(35) frightened

(36) tense

(37) anxious

(38) in good spirits

(39) cheerful

(40) happy

(41) energetic

(42) active

(43) lively
0-100 scale, with higher scores indicating better quality of life (see fig 2 for an example). The scales "social functioning", "motor functioning", and "communication" are only relevant for children aged $11 / 2$ years and older. ${ }^{19}$

The TAPQOL is available in a Dutch as well as in an English version, translated from Dutch according to international guidelines. ${ }^{20}$ 
In the last three months, has your child been...

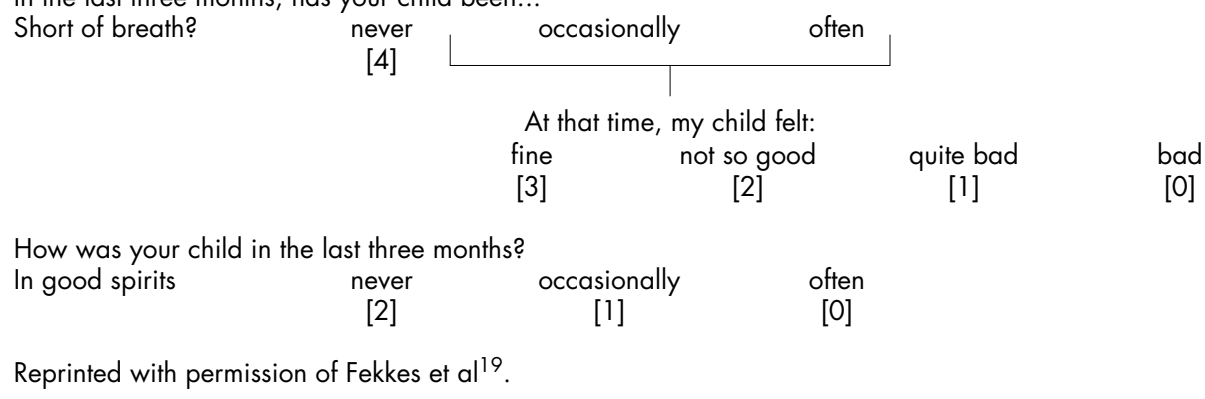

Figure 2 Example item scores TAPQOL.

Besides the TAPQOL, demographic variables and the prevalence of chronic conditions and visits to the general practitioner were assessed. Questions about chronic conditions covered: asthma or recurrent problems of the respiratory tract, recurrent otitis or having tympanostomy tubes, defective vision in which glasses are not helpful, regular abdominal pain, allergies, eczema, and other conditions.

\section{Analyses}

In accordance with the TAPQOL guidelines all items of a three item scale should be completed in order to be eligible for analysis. In scales with four items one missing answer is allowed; in the seven item scale, "problem behaviour", two missing answers were allowed. In case of non-unique answers (more than one answer per question), one answer was imputed randomly.

Feasibility of the TAPQOL was evaluated by assessing the response rate and by evaluating both the number of missing answers per item and the number of non-unique answers per item. Cronbach's alpha was used to determine the internal consistency of the scales. ${ }^{21}$ Separate analyses were made for the subgroup with two or more parent reported chronic conditions. Average correlation coefficients were calculated between items and their own scale (without the item under

\begin{tabular}{|c|c|c|c|c|c|c|c|}
\hline TAPQOL scales & $\begin{array}{l}\text { Population } \\
(n=410)\end{array}$ & Mean (SD) & Range & $\% \min ^{*}$ & $\% \max \dagger$ & Median & Cronbach's alphał \\
\hline \multirow[t]{3}{*}{ Sleeping } & Total & $79.4(19.0)$ & $13-100$ & 0.0 & 29.4 & 81.3 & 0.89 \\
\hline & Infants & $82.1(18.5)$ & $31-100$ & 0.0 & 37.4 & 87.5 & 0.88 \\
\hline & Toddlers & $78.6(19.1)$ & $13-100$ & 0.0 & 27.1 & 81.3 & 0.89 \\
\hline \multirow[t]{3}{*}{ Appetite } & Total & $84.1(13.9)$ & $33-100$ & 0.0 & 30.4 & 83.3 & 0.79 \\
\hline & Infants & $91.9(10.7)$ & $58-100$ & 0.0 & 55.6 & 100 & 0.70 \\
\hline & Toddlers & $81.9(14.0)$ & $33-100$ & 0.0 & 23.2 & 83.3 & 0.78 \\
\hline \multirow[t]{3}{*}{ Lung problems } & Total & 91.9 (16.5) & $0-100$ & 0.3 & 73.4 & 100 & 0.81 \\
\hline & Infants & $89.1(17.2)$ & $42-100$ & 0.0 & 62.9 & 100 & 0.80 \\
\hline & Toddlers & $92.7(16.2)$ & $0-100$ & 0.3 & 76.4 & 100 & 0.82 \\
\hline \multirow[t]{3}{*}{ Stomach problems } & Total & 91.6 (13.2) & $42-100$ & 0.0 & 63.3 & 100 & 0.47 \\
\hline & Infants & $90.3(14.1)$ & $42-100$ & 0.0 & 58.0 & 100 & 0.46 \\
\hline & Toddlers & 91.9 (12.9) & $50-100$ & 0.0 & 64.8 & 100 & 0.53 \\
\hline \multirow[t]{3}{*}{ Skin problems } & Total & $91.4(12.3)$ & $17-100$ & 0.0 & 48.0 & 91.7 & 0.77 \\
\hline & Infants & $92.6(10.3)$ & $50-100$ & 0.0 & 45.6 & 91.7 & 0.73 \\
\hline & Toddlers & 91.0 (12.8) & $17-100$ & 0.0 & 48.7 & 91.7 & 0.78 \\
\hline \multirow[t]{3}{*}{ Motor functioning } & Total & $97.8(8.5)$ & $25-100$ & 0.0 & 86.7 & 100 & 0.89 \\
\hline & Infants & NA & NA & NA & NA & NA & NA \\
\hline & Toddlers§ & $97.8(8.5)$ & $25-100$ & 0.0 & 86.7 & 100 & 0.89 \\
\hline \multirow{3}{*}{ Problem behaviour } & Total & 73.0 (16.9) & $14-100$ & 0.0 & 10.8 & 71.4 & 0.81 \\
\hline & Infants & $87.3(12.7)$ & $57-100$ & 0.0 & 34.4 & 85.7 & 0.73 \\
\hline & Toddlers & $68.9(15.6)$ & $14-100$ & 0.0 & 4.1 & 71.4 & 0.78 \\
\hline \multirow{3}{*}{ Social functioning } & Total & $91.8(15.3)$ & $33-100$ & 0.0 & 70.8 & 100 & 0.69 \\
\hline & Infants & NA & NA & NA & NA & NA & NA \\
\hline & Toddlers§ & 91.8 (15.3) & $33-100$ & 0.0 & 70.8 & 100 & 0.69 \\
\hline \multirow[t]{3}{*}{ Communication } & Total & 89.4 (12.7) & $31-100$ & 0.0 & 41.6 & 93.8 & 0.81 \\
\hline & Infants & NA & NA & NA & NA & NA & NA \\
\hline & Toddlers§ & 89.4 (12.7) & $31-100$ & 0.0 & 41.6 & 93.8 & 0.81 \\
\hline \multirow[t]{3}{*}{ Positive mood } & Total & $97.7(10.4)$ & $0-100$ & 0.2 & 94.4 & 100 & 0.92 \\
\hline & Infants & 97.6 (10.4) & $50-100$ & 0.0 & 94.5 & 100 & 0.97 \\
\hline & Toddlers & 97.7 (10.4) & $0-100$ & 0.3 & 94.3 & 100 & 0.91 \\
\hline \multirow{3}{*}{ Anxiety } & Total & 77.4 (18.7) & $0-100$ & 0.2 & 27.9 & 100 & 0.62 \\
\hline & Infants & $83.1(17.8)$ & $33-100$ & 0.0 & 41.1 & 83.3 & 0.56 \\
\hline & Toddlers & 75.8 (18.6) & $0-100$ & 0.3 & 24.2 & 83.3 & 0.63 \\
\hline \multirow[t]{3}{*}{ Liveliness } & Total & 96.0 (12.3) & $0-100$ & 0.2 & 88.3 & 100 & 0.76 \\
\hline & Infants & 96.0 (10.9) & $50-100$ & 0.0 & 85.7 & 100 & 0.58 \\
\hline & Toddlers & 96.1 (12.7) & $0-100$ & 0.3 & 89.0 & 100 & 0.80 \\
\hline
\end{tabular}


consideration) and between items and every other scale, to determine whether the items were well chosen and if the scales represent different domains. The average corrected item-own scale correlation coefficients are expected to be higher than the average item-other scale correlation coefficients. At the group level, test-retest reliability was assessed by the Wilcoxon signed ranks test. We used non-parametric tests, because data were skewed and TAPQOL scales are not continuous but have a lowest and highest possible value that will show ceiling effects. Cohen's effect size, ${ }^{22}$ which relates the difference in mean scores between test and retest to the dispersion of the scores of the test, were calculated: $d=$ $\left[\right.$ mean(a) - mean(b)]/SD at the test. ${ }^{22}$ At the individual level, the intra-class correlation (ICC) was applied to assess testretest reliability. ${ }^{23}$ Discriminant validity was evaluated by comparing TAPQOL scale scores of a subgroup of children with no parent reported chronic conditions with those of a subgroup of children with two or more parent reported chronic conditions. The Mann-Whitney $U$ test was used to determine differences in mean scale scores between the two groups. Cohen's effect sizes were calculated: $d=[$ mean $(\mathrm{a})-$ mean(b)]/SD of the subgroup with parent reported conditions. Comparisons were also made of TAPQOL scale scores between a subgroup of children with zero or one visit to the general practitioner and a subgroup of children with four or more visits to the general practitioner in the last year. Spearman's rank order correlation coefficients were applied to evaluate concurrent validity of the TAPQOL with a single item general health rating: "In general, would you say your child's health is: excellent, very good, good, fair, or poor".

SPSS 10.0 was used for the analysis.

\section{RESULTS}

\section{Response, feasibility, and sample characteristics}

Response rate was $83.0 \%$; five (1.2\%) questionnaires were not eligible for analysis (see methods). Response rate at the retest was $75.3 \%$; one questionnaire was not eligible for analysis; 115 retest questionnaires could be matched to a test questionnaire (same child, same respondent). Mean age of the parent respondents was 33.1 (SD 7.1) years; 97\% of the respondents were mothers. Most lived together with their partner $(98 \%) ; 50 \%$ of the respondents had a part-time job and $36 \%$ were homemakers; $33 \%$ of the respondents had an education at intermediate vocational level, 39\% had a lower, and $27 \%$ a higher educational level than intermediate vocational education.

Fifty per cent of the children eligible for analysis were girls and $22 \%$ of the children were infants (between 2 and 12 months old).

There were few missing answers on the TAPQOL (circa 1\% per item) and very few non-unique answers (less than $1 \%$ per item).

\section{Score distribution and internal consistency}

Six scales had ceiling effects (that is, $>50 \%$ of the respondents had the maximum score). When the total group

Table 2 Average inter-item, corrected item-own scale, and item-other scale correlations* of the TAPQOL scales in 410 children: 92 infants aged 2-12 months and 318 toddlers aged 12-48 months

\begin{tabular}{|c|c|c|c|c|}
\hline TAPQOL scales & Population & $\begin{array}{l}\text { Average inter-item } \\
\text { correlation }\end{array}$ & $\begin{array}{l}\text { Average item-own } \\
\text { scale correlation* }\end{array}$ & $\begin{array}{l}\text { Average item-other } \\
\text { scale correlation }\end{array}$ \\
\hline \multirow[t]{3}{*}{ Sleeping } & Total & 0.67 & 0.76 & -0.16 \\
\hline & Infants & 0.66 & 0.75 & -0.22 \\
\hline & Toddlers & 0.67 & 0.76 & -0.15 \\
\hline \multirow[t]{3}{*}{ Appetite } & Total & 0.55 & 0.63 & -0.10 \\
\hline & Infants & 0.44 & 0.52 & -0.17 \\
\hline & Toddlers & 0.54 & 0.62 & -0.09 \\
\hline \multirow[t]{3}{*}{ Lung problems } & Total & 0.58 & 0.67 & -0.10 \\
\hline & Infants & 0.56 & 0.64 & -0.15 \\
\hline & Toddlers & 0.59 & 0.68 & -0.10 \\
\hline \multirow[t]{3}{*}{ Stomach problems } & Total & 0.22 & 0.30 & -0.09 \\
\hline & Infants & 0.22 & 0.29 & -0.16 \\
\hline & Toddlers & 0.25 & 0.36 & -0.09 \\
\hline \multirow[t]{3}{*}{ Skin problems } & Total & 0.53 & 0.61 & -0.05 \\
\hline & Infants & 0.48 & 0.55 & -0.08 \\
\hline & Toddlers & 0.55 & 0.62 & -0.05 \\
\hline \multirow[t]{3}{*}{ Motor functioning } & Total & 0.67 & 0.76 & -0.10 \\
\hline & Infants & NA & NA & NA \\
\hline & Toddlers $†$ & 0.67 & 0.76 & -0.10 \\
\hline \multirow[t]{3}{*}{ Problem behaviour } & Total & 0.38 & 0.55 & -0.11 \\
\hline & Infants & 0.27 & 0.45 & -0.15 \\
\hline & Toddlers & 0.33 & 0.50 & -0.10 \\
\hline \multirow[t]{3}{*}{ Social functioning } & Total & 0.44 & 0.52 & 0.07 \\
\hline & Infants & NA & NA & NA \\
\hline & Toddlers $\dagger$ & 0.44 & 0.52 & 0.07 \\
\hline \multirow[t]{3}{*}{ Communication } & Total & 0.51 & 0.63 & -0.09 \\
\hline & Infants & NA & NA & NA \\
\hline & Toddlers $\dagger$ & 0.51 & 0.63 & -0.09 \\
\hline \multirow[t]{3}{*}{ Positive mood } & Total & 0.79 & 0.84 & 0.15 \\
\hline & Infants & 0.93 & 0.94 & 0.23 \\
\hline & Toddlers & 0.76 & 0.81 & 0.14 \\
\hline \multirow[t]{3}{*}{ Anxiety } & Total & 0.35 & 0.43 & -0.10 \\
\hline & Infants & 0.29 & 0.37 & -0.11 \\
\hline & Toddlers & 0.36 & 0.44 & -0.09 \\
\hline \multirow[t]{3}{*}{ Liveliness } & Total & 0.57 & 0.63 & 0.05 \\
\hline & Infants & 0.33 & 0.41 & 0.05 \\
\hline & Toddlers & 0.64 & 0.70 & 0.05 \\
\hline
\end{tabular}




\begin{tabular}{|c|c|c|c|c|c|c|}
\hline TAPQOL scales & Population & Test mean (SD) & Retest mean (SD) & $p$ value (WSR) $\dagger$ & Effect sizeł & $\begin{array}{l}\text { Intra-class correlation } \\
\text { Test-retest }\end{array}$ \\
\hline \multirow[t]{3}{*}{ Sleeping } & Total & 79 (19) & $79(18)$ & 0.96 & -0.02 & $0.65^{*}$ \\
\hline & Infants & $88(14)$ & $86(17)$ & 0.49 & -0.11 & $0.63^{*}$ \\
\hline & Toddlers & $76(19)$ & $76(18)$ & 0.70 & 0.0 & $0.63^{*}$ \\
\hline \multirow{3}{*}{ Appetite } & Total & 84 (14) & 85 (14) & 0.33 & 0.05 & $0.69^{*}$ \\
\hline & Infants & $96(8)$ & $92(13)$ & 0.20 & -0.50 & 0.19 \\
\hline & Toddlers & 81 (14) & 83 (14) & 0.05 & 0.17 & $0.76^{*}$ \\
\hline \multirow[t]{3}{*}{ Lung problems } & Total & $92(17)$ & $93(15)$ & 0.18 & 0.08 & $0.74^{*}$ \\
\hline & Infants & $95(11)$ & $99(5)$ & 0.02 & 0.33 & $0.63^{*}$ \\
\hline & Toddlers & $91(18)$ & $91(16)$ & 0.67 & 0.03 & $0.74^{\star}$ \\
\hline \multirow[t]{3}{*}{ Stomach problems } & Total & 91 (13) & $90(14)$ & 0.94 & -0.03 & $0.35^{*}$ \\
\hline & Infants & $92(14)$ & $96(7)$ & 0.20 & 0.29 & 0.02 \\
\hline & Toddlers & $90(13)$ & $88(15)$ & 0.43 & -0.14 & $0.41^{*}$ \\
\hline \multirow[t]{3}{*}{ Skin problems } & Total & $92(11)$ & 93 (11) & 0.14 & 0.09 & $0.84^{*}$ \\
\hline & Infants & $94(7)$ & $95(8)$ & 0.78 & 0.04 & $0.70^{*}$ \\
\hline & Toddlers & 91 (12) & $92(12)$ & 0.13 & 0.10 & $0.86^{*}$ \\
\hline \multirow[t]{3}{*}{ Motor functioning } & Total & $98(9)$ & 97 (12) & 0.16 & -0.14 & $0.88^{*}$ \\
\hline & Infants & NA & NA & NA & NA & NA \\
\hline & Toddlers§ & $98(9)$ & $97(12)$ & 0.16 & -0.14 & $0.88^{*}$ \\
\hline \multirow[t]{3}{*}{ Problem behaviour } & Total & $72(19)$ & $73(16)$ & 0.28 & 0.05 & $0.81^{*}$ \\
\hline & Infants & $91(11)$ & $89(8)$ & 0.30 & -0.18 & $0.57^{*}$ \\
\hline & Toddlers & $65(16)$ & 67 (15) & 0.09 & 0.13 & $0.74^{*}$ \\
\hline \multirow[t]{3}{*}{ Social functioning } & Total & $92(15)$ & 95 (11) & 0.05 & 0.21 & $0.51^{*}$ \\
\hline & Infants & NA & NA & NA & NA & NA \\
\hline & Toddlers§ & $92(15)$ & $95(11)$ & 0.05 & 0.21 & $0.51^{*}$ \\
\hline \multirow[t]{3}{*}{ Communication } & Total & $88(14)$ & $90(11)$ & 0.13 & -0.13 & $0.68^{*}$ \\
\hline & Infants & & & NA & NA & NA \\
\hline & Toddlers§ & $88(14)$ & $90(11)$ & 0.13 & -0.13 & $0.68^{*}$ \\
\hline \multirow[t]{3}{*}{ Positive mood } & Total & 96 (14) & 96 (14) & 0.77 & 0.03 & $0.48^{*}$ \\
\hline & Infants & $98(10)$ & $98(9)$ & 0.32 & 0.06 & $0.95^{\star}$ \\
\hline & Toddlers & $95(16)$ & 96 (15) & 0.89 & 0.02 & $0.42^{\star}$ \\
\hline \multirow[t]{3}{*}{ Anxiety } & Total & $76(21)$ & $78(20)$ & 0.14 & 0.13 & $0.50^{\star}$ \\
\hline & Infants & $84(20)$ & 94 (12) & 0.02 & 0.51 & 0.25 \\
\hline & Toddlers & $73(20)$ & $73(20)$ & 0.77 & 0.0 & $0.50^{*}$ \\
\hline \multirow{3}{*}{ Liveliness } & Total & $97(10)$ & $96(13)$ & 0.15 & -0.14 & $0.62^{*}$ \\
\hline & Infants & 96 (11) & $98(10)$ & 0.41 & 0.10 & $0.74^{*}$ \\
\hline & Toddlers & $98(9)$ & 95 (14) & 0.06 & -0.23 & $0.59^{*}$ \\
\hline
\end{tabular}

${ }^{*} \mathrm{p}<0.01$.

†Non-parametric test for differences between the average scale scores at the test and at the retest: two-sided Wilcoxon signed ranks test. \#Differences between the means divided by SD at the first measurement.

$\S$ Only for children aged 18 months or older $(n=76)$.

NA, not applicable.

showed a ceiling effect, then both the infants and toddlers as subgroups did so. On only one item ("appetite") did the subgroup infants show a ceiling effect whereas the subgroup toddlers and total group did not. In the total group, nine scales had Cronbach's alpha $>0.70$. The subgroup infants (except for "liveliness") and the subgroup toddlers showed sufficient internal consistency for the same scales as the total group, but in general, the subgroup infants had somewhat lower Cronbach's alphas than the subgroup toddlers (table 1). For the subgroup with two or more parent reported chronic conditions, five scales (same scales as for the total group except for "lung problems") showed ceiling effects. Overall, the percentages of respondents with a maximum score were lower in this subgroup than in the total group. In this subgroup, eight scales had Cronbach's alphas $>0.70$. These were the same scales as in the total group; only liveliness showed in this subgroup a Cronbach's alpha below 0.70.

There were no differences with regard to scale means between boys and girls, except that girls had a higher mean score than boys on the scale "communication" ( $p<0.01)$.

All scales had higher average corrected item-own scale correlation coefficients than the corresponding average itemother scale correlation coefficients in the total group, as well as in the subgroups infants and toddlers (table 2).

\section{Test-retest reliability}

In the total group there were no significant differences in mean scale scores between test and retest. The subgroup infants showed significant differences between mean scores for "lung problems" and "anxiety"; toddlers did not show significant differences. Two scales in the total group, three scales in the subgroup infants, and two scales in the subgroup toddlers had an ICC $<0.50$. For most scales ICCs were lower in the subgroup of infants than in the subgroup of toddlers, except for "liveliness and "positive mood" (table 3 ).

\section{Discriminant validity}

The most prevalent parent reported chronic conditions were asthma $(20 \%)$, eczema $(14 \%)$, and regular otitis or having tympanostomy tubes ( $11 \%)$; the remainder of the conditions were prevalent in less than $6 \%$ of the children. For the total group, five scales ("sleeping", "appetite", "lung problems", "skin problems", and "problem behaviour") showed significantly different mean scores between the subgroup of children with zero parent reported chronic conditions versus the subgroup of children with two or more conditions. Cohen's effect sizes were large for the scales "lung problems" and "skin problems". In general, the subgroup infants showed the same effect sizes as the subgroup toddlers, except for "sleeping" and "lung problems", where the effect sizes for the subgroup infants were much larger than for the subgroup toddlers (table 4 ).

For the number of visits to the general practitioner, six scales ("sleeping", "appetite", "lung problems", "stomach problems", "skin problems", and "problem behaviour") showed significant mean scale score differences between 


\begin{tabular}{|c|c|c|c|c|c|c|}
\hline \multirow[b]{2}{*}{ TAPQOL scales } & \multirow[b]{2}{*}{ Population } & \multicolumn{5}{|c|}{ Number of parent reported chronic conditions per child } \\
\hline & & $\begin{array}{l}0 \text { conditions } \\
n=240 \\
\text { Mean (SD) }\end{array}$ & $\begin{array}{l}1 \text { condition } \\
n=113 \\
\text { Mean (SD) }\end{array}$ & $\begin{array}{l}1 \text { v } 0 \text { conditions } \\
\text { Effect size } \\
\text { Sizet }\end{array}$ & $\begin{array}{l}\geqslant 2 \text { conditions } \\
\mathrm{n}=57 \\
\text { Mean (SD) }\end{array}$ & $\begin{array}{l}\geqslant 2 v 0 \text { conditions } \\
\text { Effect size }\end{array}$ \\
\hline \multirow[t]{3}{*}{ Sleeping } & Total & $83(18)$ & $77(19)$ & $0.34^{* *}$ & $69(21)$ & $0.68^{* *}$ \\
\hline & Infants & $86(16)^{1}$ & $81(20)^{2}$ & 0.27 & $62(16)^{3}$ & $1.50^{* *}$ \\
\hline & Toddlers & $82(18)^{4}$ & $76(18)^{5}$ & $0.35^{\star *}$ & $71(21)^{6}$ & $0.53^{* *}$ \\
\hline \multirow[t]{3}{*}{ Appetite } & Total & $85(14)$ & 85 (13) & 0.04 & 79 (17) & $0.34^{*}$ \\
\hline & Infants & $93(10)$ & $90(11)$ & 0.27 & $88(14)$ & $0.39^{*}$ \\
\hline & Toddlers & $83(14)$ & $83(13)$ & -0.03 & 77 (17) & 0.31 \\
\hline \multirow[t]{3}{*}{ Lung problems } & Total & $97(10)$ & $89(19)$ & $0.40^{* *}$ & $75(22)$ & $1.02^{* *}$ \\
\hline & Infants & $96(10)$ & $85(17)$ & $0.64^{* *}$ & $60(17)$ & $2.18^{* *}$ \\
\hline & Toddlers & $97(9)$ & $90(20)$ & $0.34^{* *}$ & $78(21)$ & $0.88^{* *}$ \\
\hline \multirow[t]{3}{*}{ Stomach problems } & Total & 93 (12) & 91 (14) & 0.12 & 88 (16) & 0.29 \\
\hline & Infants & $92(13)$ & $89(15)$ & 0.17 & 86 (19) & 0.30 \\
\hline & Toddlers & 93 (12) & $92(13)$ & 0.10 & $88(16)$ & 0.29 \\
\hline \multirow{3}{*}{ Skin problems } & Total & $96(6)$ & $88(13)$ & $0.60^{* *}$ & 80 (19) & $0.80^{* *}$ \\
\hline & Infants & $96(6)$ & 91 (12) & 0.40 & $81(17)$ & $0.87^{* *}$ \\
\hline & Toddlers & $96(6)$ & 87 (13) & $0.64^{* *}$ & $80(20)$ & $0.78^{* *}$ \\
\hline \multirow{3}{*}{ Motor functioning } & Total & $99(7)$ & 97 (11) & 0.18 & $96(9)$ & 0.27 \\
\hline & Infants & NA & NA & NA & NA & NA \\
\hline & Toddlers $\ddagger$ & $99(7)$ & $97(11)$ & 0.18 & $96(9)$ & 0.27 \\
\hline \multirow[t]{3}{*}{ Problem behaviour } & Total & 73 (17) & 75 (16) & -0.10 & 67 (17) & $0.38^{*}$ \\
\hline & Infants & $88(11)$ & $90(13)$ & -0.14 & $80(17)$ & 0.45 \\
\hline & Toddlers & $69(16)$ & $71(15)$ & -0.14 & $64(16)$ & 0.34 \\
\hline \multirow[t]{3}{*}{ Social functioning } & Total & $93(15)$ & $90(18)$ & 0.14 & $92(12)$ & 0.04 \\
\hline & Infants & NA & NA & NA & NA & NA \\
\hline & Toddlers $\ddagger$ & $93(15)$ & $90(18)$ & 0.14 & $92(12)$ & 0.04 \\
\hline \multirow[t]{3}{*}{ Communication } & Total & 91 (11) & 88 (15) & 0.19 & $87(16)$ & 0.25 \\
\hline & Infants & & & NA & & NA \\
\hline & Toddlers $\ddagger$ & $91(11)$ & $88(15)$ & 0.19 & 87 (16) & 0.25 \\
\hline \multirow[t]{3}{*}{ Positive mood } & Total & 98 (8) & 97 (12) & 0.08 & 95 (15) & 0.23 \\
\hline & Infants & 98 (10) & $100(0)$ & NA & $91(20)$ & 0.35 \\
\hline & Toddlers & 99 (7) & 97 (14) & 0.13 & 96 (13) & 0.20 \\
\hline \multirow[t]{3}{*}{ Anxiety } & Total & 78 (19) & 79 (17) & -0.06 & 74 (19) & 0.18 \\
\hline & Infants & 84 (18) & 84 (13) & 0.01 & $76(23)$ & 0.37 \\
\hline & Toddlers & 76 (19) & 77 (18) & -0.09 & 74 (18) & 0.09 \\
\hline \multirow[t]{3}{*}{ Liveliness } & Total & 96 (12) & 97 (13) & -0.05 & 95 (12) & 0.05 \\
\hline & Infants & 96 (12) & $98(6)$ & -0.42 & 94 (15) & 0.10 \\
\hline & Toddlers & $96(13)$ & 96 (14) & -0.01 & $96(11)$ & 0.04 \\
\hline \multicolumn{7}{|c|}{$\begin{array}{l}\text { *Significant at the } 0.05 \text { level. } \\
\text { **Significant at the } 0.01 \text { level. } \\
\text { †Differences of the means divided by SD in the subgroup with condition(s). } \\
\text { †Only for children aged } 18 \text { months old or older. } \\
\text { NA, not applicable. }\end{array}$} \\
\hline
\end{tabular}

the subgroup of children with zero or one visit and the subgroup of children with four or more visits in the last year for the total group. "Appetite" and "stomach problems" showed no significant differences in the subgroup infants. The scales "sleeping" and "lung problems" had large Cohen's effect sizes, especially in the subgroup infants.

\section{Concurrent validity}

There were low but significant Spearman's correlation coefficients in the expected direction between nine TAPQOL scales and a single item general health rating. Six of the nine scales suitable for the subgroup infants showed larger correlation coefficients between TAPQOL scales and a single item general health rating than in the subgroup toddlers (table 5).

\section{DISCUSSION}

This study, with a very high response rate, ${ }^{24}$ established the feasibility of the parent completed TAPQOL questionnaire for preschool children in a large general population sample; psychometric properties were generally adequate in the total group as well as in the subgroups infants and toddlers.

Because our study was limited to a random general population sample, we could not evaluate the applicability of the TAPQOL in clinical populations. We had only one cross-sectional assessment and a retest; therefore, we could not evaluate responsiveness to change in health status over time. Another limitation is that we are unaware of the adequacy of proxy rating (by parents) which are indispensable for this age group. Proxy rating may be confounded by many factors..$^{132526}$

Our results can be compared only with those from the study by Fekkes and colleagues, ${ }^{14}$ and our data confirm their results concerning ceiling effects. The phenomenon "ceiling effects" may limit the use of the TAPQOL to detect changes and to describe health beyond the average in relatively healthy populations. In general, our Cronbach's alphas were somewhat higher than in the study of Fekkes et al, but especially for "skin problems", "motor functioning", "communication", and "positive mood" our Cronbach's alphas were much higher than reported by Fekkes and colleagues. ${ }^{14}$ For discriminant validity, both Fekkes et al and our study found significant differences in mean scale scores in the physical functioning domain for children with and without parent reported chronic conditions.

Test-retest reliability was low for some scales; a phenomenon that has also been reported in evaluations of other instruments. ${ }^{27} 28$ For the scales "stomach problems" and 


\begin{tabular}{|c|c|c|c|}
\hline \multirow[b]{2}{*}{ TAPQOL scales } & \multirow[b]{2}{*}{ Population } & \multicolumn{2}{|c|}{ Single item general health rating } \\
\hline & & $\begin{array}{l}\text { Spearman rho } \\
\text { correlation } \\
\text { coefficient }\end{array}$ & $\begin{array}{l}\text { Pearson } r \\
\text { correlation } \\
\text { coefficient }\end{array}$ \\
\hline \multirow[t]{3}{*}{ Sleeping } & Total & $0.36^{* *}$ & $0.35^{\star \star}$ \\
\hline & Infants & $0.42^{\star *}$ & $0.39^{* *}$ \\
\hline & Toddlers & $0.34^{* *}$ & $0.33^{* \star}$ \\
\hline \multirow{3}{*}{ Appetite } & Total & $0.24^{* *}$ & $0.25^{* *}$ \\
\hline & Infants & $0.28^{* *}$ & $0.31^{* *}$ \\
\hline & Toddlers & $0.22^{* *}$ & $0.24^{* *}$ \\
\hline \multirow[t]{3}{*}{ Lung problems } & Total & $0.34^{* *}$ & $0.40^{* *}$ \\
\hline & Infants & $0.55^{\star \star}$ & $0.59^{* *}$ \\
\hline & Toddlers & $0.28^{\star *}$ & $0.34^{* *}$ \\
\hline \multirow{3}{*}{ Stomach problems } & Total & $0.16^{* *}$ & $0.21^{* *}$ \\
\hline & Infants & $0.26^{*}$ & $0.34^{* *}$ \\
\hline & Toddlers & $0.14^{*}$ & $0.17^{* *}$ \\
\hline \multirow[t]{3}{*}{ Skin problems } & Total & $0.13^{\star *}$ & $0.16^{* *}$ \\
\hline & Infants & 0.08 & $0.16^{* *}$ \\
\hline & Toddlers & $0.15^{* *}$ & $0.16^{* *}$ \\
\hline \multirow[t]{3}{*}{ Motor functioning } & Total & $0.13^{*}$ & $0.19^{* *}$ \\
\hline & Infants & NA & NA \\
\hline & Toddlers $\ddagger$ & $0.13^{*}$ & $0.19^{* *}$ \\
\hline \multirow[t]{3}{*}{ Problem behaviour } & Total & 0.09 & 0.09 \\
\hline & Infants & 0.08 & 0.11 \\
\hline & Toddlers & 0.05 & 0.07 \\
\hline \multirow[t]{3}{*}{ Social functioning } & Total & 0.10 & 0.11 \\
\hline & Infants & NA & NA \\
\hline & Toddlersł & 0.10 & 0.11 \\
\hline \multirow[t]{3}{*}{ Communication } & Total & $0.18^{\star *}$ & $0.21^{* *}$ \\
\hline & Infants & NA & NA \\
\hline & Toddlers $\ddagger$ & $0.18^{* *}$ & $0.21^{* *}$ \\
\hline \multirow[t]{3}{*}{ Positive mood } & Total & $0.12^{*}$ & $0.17^{\star *}$ \\
\hline & Infants & $0.28^{* *}$ & $0.33^{* *}$ \\
\hline & Toddlers & 0.08 & $0.12^{*}$ \\
\hline \multirow[t]{3}{*}{ Anxiety } & Total & $0.15^{* *}$ & $0.14^{* *}$ \\
\hline & Infants & $0.37^{* *}$ & $0.28^{* *}$ \\
\hline & Toddlers & 0.08 & 0.10 \\
\hline \multirow[t]{3}{*}{ Liveliness } & Total & 0.03 & 0.04 \\
\hline & Infants & -0.04 & 0.08 \\
\hline & Toddlers & 0.05 & 0.03 \\
\hline \multicolumn{4}{|c|}{$\begin{array}{l}{ }^{*} \text { Significant at the } 0.05 \text { level. } \\
\text { * } \text { Significant at the } 0.01 \text { level. } \\
\text { NA, not applicable. } \\
\text { fOnly for children aged } 18 \text { months or older }(n=264)\end{array}$} \\
\hline
\end{tabular}

"anxiety" the Cronbach's alpha is also low. We suggest further research on this topic, as test-retest reliability should be adequately shown, especially in studies with repeated measurements.

Ceiling effects were present in the total group as well as in the subgroup with parent reported chronic conditions, although in the subgroup to a lesser degree (five scales instead of six scales with ceiling effects and fewer respondents with maximum scores). This can be interpreted as follows. The chronic conditions mentioned by the parent mostly affected physical functioning. The scales belonging to this domain did show differences between children with and without parent reported chronic conditions. The other domains seemed not to be affected in these conditions. We suggest further evaluation of the TAPQOL in patient groups with distinct conditions that affect the emotional, social, and cognitive TAPQOL domains, such as children with attention deficit hyperactivity disorder (ADHD) or mental retardation.

In conclusion, our study that was conducted in the setting of community medicine showed that the TAPQOL is a feasible and reliable instrument to measure health status and health related quality of life. Our results suggest that the TAPQOL will also be applicable in the clinical setting with conditions that affect physical functioning, since it clearly discriminated between children with and without parent reported chronic conditions with a physical nature. Although the TAPQOL was not originally designed for infants, our study supports the reliability and discriminative validity of the majority of its scales, not only for toddlers but also for infants. We propose further research, including cross-cultural validation, ${ }^{29}$ evaluations in clinical samples, and evaluations of responsiveness to community or clinical interventions.

\section{ACKNOWLEDGEMENTS}

Community Care Salland was responsible for the data collection. We like to thank the physicians, nurses, physician's assistants, and managers of the Home Care for facilitating this project. We are also very grateful to the parents who participated in this study.

\section{Authors' affiliations}

E M Bunge, M-L Essink-Bot, H Raat, Department of Public Health, Erasmus MC, University Medical Center Rotterdam, Netherlands M P H M Kobussen, Community Care Salland, Ommen, Netherlands L W A van Suijlekom-Smit, H A Moll, Department of Paediatrics, Erasmus MC-University Medical Center Rotterdam, Netherlands H Raat, GGD-Municipal Health Service, Rotterdam, Netherlands

Funding: This study was funded by the Netherlands Organisation for Health Research and Development (ZonMw) NWO-Health Care Efficiency Research Program Grant \# 2200.0128

Competing interests: none declared 


\section{REFERENCES}

1 Eiser C. Children's quality of life measures. Arch Dis Child 1997;77:350-4.

2 Connolly MA, Johnson JA. Measuring quality of life in paediatric patients. Pharmacoeconomics 1999;16:605-25.

3 Jenney ME, Campbell S. Measuring quality of life. Arch Dis Child 1997;77:347-50.

4 Lohr KN. Health outcomes methodology symposium: summary and recommendations. Med Care 2000;38(9 suppl):I1194-208.

5 Brazier J, Deverill M, Green C, et al. A review of the use of health status measures in economic evaluation. Health Technol Assess 1993;3(9):i-iv, 1-164.

6 Gold MR, Siegel JE, Russel LB, et al. Cost-effectiveness in health and medicine. New York/Oxford: Oxford University Press, 1996.

7 Manuel DG, Schultz SE, Kopec JA. Measuring the health burden of chronic disease and injury using health adjusted life expectancy and the Health Utilities Index. J Epidemiol Community Health 2002;56:843-50.

8 Gold MR, Muennig P. Measure-dependent variation in burden of disease estimates: implications for policy. Med Care 2002;40:260-6.

9 Taylor A, Butt W, Ciardulli M. The functional outcome and quality of life of children after admission to an intensive care unit. Intensive Care Med 2003;29:795-800.

10 Higginson IJ, Carr AJ. Measuring quality of life: using quality of life measures in the clinical setting. BMJ 2001;322:1297-300.

11 Stein RE, Jessop DJ. Functional status II(R). A measure of child health status. Med Care 1990;28:1041-55.

12 Gemke RJ, Bonsel GJ. Reliability and validity of a comprehensive health status measure in a heterogeneous population of children admitted to intensive care. $J$ Clin Epidemiol 1996;49:327-33.

13 Hack M. Consideration of the use of health status, functional outcome, and quality-of-life to monitor neonatal intensive care practice. Pediatrics 1999; 103(1 suppl E):319-28.

14 Fekkes M, Theunissen NC, Brugman E, et al. Development and psychometric evaluation of the TAPQOL: a health-related quality of life instrument for 1-5year-old children. Qual Life Res 2000:9:961-72.

15 Sturms LM, van der Sluis CK, Groothoff JW, et al. The health-related quality of life of pediatric traffic victims. J Trauma 2002;52:88-94.
16 Veen S, Fekkes M, Koopman HM, et al. Quality of life in preschool children born preterm. Dev Med Child Neurol 2001;43:460-5.

17 Rovers MM, Krabbe PF, Straatman H, et al. Randomised controlled trial of the effect of ventilation tubes (grommets) on quality of life at age 1-2 years. Arch Dis Child 2001;84:45-9.

18 Behrman RE, Kliegman RM, Arvin AM, Nelson WE, eds. Nelson textbook of pediatrics, 15th edn. Philadelphia: WB Saunders Company, 1996.

19 TNO. TNO-AZL pre-school children quality of life users manual. TNO PG, Leiden, Netherlands, 2004

20 Guillemin F, Bombardier C, Beaton D. Cross-cultural adaptation of healthrelated quality of life measures: literature review and proposed guidelines. J Clin Epidemiol 1993:46:1417-32.

21 Bland JM, Altman DG. Cronbach's alpha. BMJ 1997;314:572.

22 Cohen J. Statistical power analysis for the behavioral sciences. New York: Academic Press, 1977.

23 Deyo RA, Diehr P, Patrick DL. Reproducibility and responsiveness of health status measures. Statistics and strategies for evaluation. Control Clin Trials $1991 ; 12(4$ suppl): 142S-158S

24 Asch DA, Jedrziewski MK, Christakis NA. Response rates to mail surveys published in medical journals. J Clin Epidemiol 1997:50:1129-36.

25 Addington-Hall J, Kalra L. Who should measure quality of life? BMJ 2001;322:1417-20

26 Waters E, Doyle J, Wolfe R, et al. Influence of parental gender and selfreported health and illness on parent-reported child health. Pediatrics 2000; 106:1422-8

27 Raat $\mathbf{H}$, Landgraf JM, Bonsel GJ, et al. Reliability and validity of the child health questionnaire-child form (CHQ-CF87) in a Dutch adolescent population. Qual Life Res 2002;11:575-81.

28 Vogels T, Verrips GH, Verloove-Vanhorick SP, et al. Measuring health-related quality of life in children: the development of the TACQOL parent form. Qual Life Res 1998;7:457-65

29 Anderson RT, Aaronson NK, Bullinger $M$, et al. A review of the progress towards developing health-related quality-of-life instruments for international clinical studies and outcomes research. Pharmacoeconomics $1996 ; 10: 336-55$

\section{Register now!}

10th European Forum on Quality Improvement in Health Care 13-15 April 2005, ExCel Conference Centre, London For further information on how to register please go to: http://www.quality.bmipg.com 